\title{
GENETIC EVIDENCE FOR NUCLEAR LOCATION OF 2-MICRON DNA IN YEAST
}

\author{
by \\ MORTEN C. KIELLAND-BRANDT, BARBARA WILKEN, STEEN HOLMBERG \\ and JENS G. LITSKE PETERSEN \\ Department of Physiology, Carlsberg Laboratory \\ Gamle Carlsberg Vej 10, DK-2500 Copenhagen Valby \\ and \\ TORSTEN NILSSON-TILLGREN \\ Institute of Genetics, University of Copenhagen \\ Øster Farimagsgade 2A, DK-1353 Copenhagen K
}

Keywords: omicron DNA, yeast plasmid, Saccharomyces plasmid, cytoduction, heteroplasmon, heterokaryon

\begin{abstract}
Progeny from karl $\times K A R I$ crosses in Saccharomyces cerevisiae were isolated by selection for a mitochondrial marker from each parent. Haploid progeny (heteroplasmons, cytoductants) were obtained at high frequency because of the kar mutation and were identified by replication of progeny colonies to media differentiating on the basis of chromosomal markers. In some of the crosses nuclei of both parental types were found among the progeny, although the $K A R I$ nuclei were in majority.

In crosses where only one parent contained the plasmid 2-micron DNA, all progeny inheriting the nucleus from that parent also had the plasmid, whereas only about $25-50 \%$ of the progeny with the other nucleus had the plasmid. In crosses where the size of 2-micron DNA of the parents was different, the haploid progeny had a plasmid size identical to that of the parent from which it had received its nucleus.

On the basis of these observations we suggest a nuclear location of 2-micron DNA. We propose that one or a few copies of the plasmid are frequently transferred from one nucleus to another in karl mediated transient heterokaryons.
\end{abstract}

Abbreviations: can = canavanine, ery = erythromycin, leu $=$ leucine, oli $=$ oligomycin, $\mathrm{SC}=$ synthetic complete dextrose, $\mathrm{SCE}=$ sorbitol citrate EDTA, YPD = yeast extract peptone dextrose, YPG = yeast extract peptone glycerol. 


\section{INTRODUCTION}

Most laboratory strains of Saccharomyces cerevisiae contain a circular DNA plasmid, 2micron DNA, at 50-100 copies per cell. Its replication is under the same genetic and physiological controls as the nuclear DNA (9) and is as such distinct from the mitochondrial DNA (11). Each copy is replicated once in the first part of S-phase (16).

The Mendelian mutation karl affects karyogamy, so that haploid clones with the parental nuclear genotype of one parent and a cytoplasmic marker from the other parent can easily be obtained (2). LIVINGSTON (6) used this mutation to study the inheritance of 2-micron DNA. He crossed a strain with the genotype $c y h\left[\mathrm{rho}^{-} \mathrm{cir}^{\circ}\right]$ with one being karl his 4 ade $2\left[\mathrm{RHO}^{+} \mathrm{Cir}^{+}\right]$( $\mathrm{cir}^{\circ}$ and $\mathrm{cir}^{+}$meaning absence and presence of 2 micron DNA, respectively). Livingston found that half of the $c y h\left[\mathrm{RHO}^{+}\right]$cytoductants had 2 micron DNA and stated that one possible interpretation of this observation would be that the copies of the plasmid are clustered within a cytoplasmic organelle. Another interpretation would be that the plasmid has a nuclear location and that one or some copies may be transferred from one nucleus to another in the transient heterokaryons produced in crosses involving karl. This possibility has gained some support by several recent observations. First, similar transfer of a whole chromosome has been observed at low frequency by us (12) and S. DUTCHER and L. HARTWELL (personal communication). Secondly, 2-micron DNA is organized with histones in the same way as chromosomal
DNA $(7,10)$. We have proposed a nuclear location of a yeast plasmid constructed in vitro by combining 2-micron DNA with a chromosomal fragment, since it was transferred at a rather low frequency during $k a r l$ mediated cytoduction (5).

In the present paper we report on crosses in which the parents carry different sizes of 2micron DNA and one parent carries karl. In order to recover progeny of both parent nuclear genotypes we used mitochondrial drug resistance markers to select for clones known to be derived from transient heterokaryons. The size of the plasmid in the progeny clones was determined. Analogous crosses were carried out in which one parent was cir $^{\circ}$ for comparison with the data of LIVINGSTON (6).

\section{MATERIALS AND METHODS}

\subsection{Media}

SC, YPD and YPG have been described (5). SC was made without serine, aspartic acid and glutamic acid. Cycloheximide resistance was tested by replication to YPD containing 0.5 $\mu \mathrm{g} \cdot \mathrm{ml}^{-1}$ of cycloheximide. Selection and test for canavanine resistance was done on $\mathrm{SC}$ without arginine and with $60 \mu \mathrm{g} \cdot \mathrm{ml}^{-1} \mathrm{~L}$-canavanine Selection and test for erythromycin and/or oligomycin resistance were done on YPG buffered with $0.1 \mathrm{M}$-sodium phosphate, $\mathrm{pH} 6.2$ and containing $5 \mathrm{mg} \cdot \mathrm{ml}^{-1}$ erythromycin and/or $3 \mu \mathrm{g} \cdot \mathrm{ml}^{-1}$ oligomycin. These two drugs were added after autoclavation, as a solution in ethanol, giving an ethanol concentration of no

Table I

Yeast strains used in this study.

\begin{tabular}{|c|c|c|}
\hline Strain & Genotype & Source \\
\hline K5-20B & MATa leul karl-I $\left[\mathrm{cir}^{+}-1\right]$ & J. CONDE (2) \\
\hline C79-839 & MATa leul karl-I [ERY $\left.\mathrm{cir}^{+}-1\right]$ & Mutant of K5-20B \\
\hline C79-840 & MATa leul karl-1 [OLI cir +-1$]$ & Mutant of K5-20B \\
\hline $\mathrm{HQ} / 5 \mathrm{C}$ & $M A T \alpha\left[\mathrm{cir}^{+}-\mathrm{s}\right]$ & LIVINGSTON (6) \\
\hline C79-828 & $M A T \alpha \operatorname{can}\left[\mathrm{cir}^{+}-\mathrm{s}\right]$ & Mutant of $\mathrm{HQ} / 5 \mathrm{C}$ \\
\hline C79-838 & MATa can [ERY $\operatorname{cir}^{+}-\mathrm{s}$ ] & Mutant of C79-828 \\
\hline C79-843 & MAT $\alpha$ can [OLI $\left.\mathrm{cir}^{+}-\mathrm{s}\right]$ & Mutant of C79-828 \\
\hline Y379-5D cyhr & $M A T \alpha \operatorname{cyh}\left[\mathrm{cir}^{\circ}\right]$ & LIVINGSTON (6) \\
\hline C79-878 & $M A T \alpha c y h\left[E R Y \operatorname{cir}^{\circ}\right]$ & Mutant of Y 379-5D cyh ${ }^{\mathrm{r}}$ \\
\hline C79-842 & $M A T \alpha \operatorname{cyh}\left[\mathrm{OLI} \mathrm{cir}^{\circ}\right]$ & Mutant of Y379-5D cyhr \\
\hline
\end{tabular}


more than $2 \%$ in the final medium. Sporulation ability was determined by replication to sporulation medium (13), incubation for 3 days at $30^{\circ} \mathrm{C}$ and staining according to SCHAEFFER and FULTON (15).

\subsection{Strains}

Strains used are listed in Table I.

Canavanine resistant mutants were derived by UV-irradiation to a survival of 0.6 .

Mitochondrially inherited mutations for resistance to erythromycin and oligomycin were induced with manganese ions according to PuTRAMENT et al. (14). On the basis of the high specificity of this mutagen the isolated mutants were assumed to be mitochondrial. The conclusions of this paper do not depend on this assumption.

\subsection{Crosses}

One tenth $\mathrm{ml}$ of a YPD culture of each parent grown for 2 days to stationary phase was used. They were mixed in $5 \mathrm{ml} \mathrm{YPD}$ and applied to a washed $25 \mathrm{~mm}$ Millipore filter (type HAWP) which was subsequently placed on a prewarmed YPD plate at $30^{\circ} \mathrm{C}$ for 3 hours. The cells were then suspended in YPD at about $10^{5}$ cells per $\mathrm{ml}$ and shaken for further 3 hours at $30^{\circ} \mathrm{C}$ after which they were plated on selective (YPG + ery + oli) and non-selective (YPD) medium.

\subsection{Determination of presence and size of 2 - micron DNA}

Spheroplasts (11) were washed and suspended in SCE (11). Lysis and removal of most chromosomal DNA and other cell constituents by co-precipitation with sodium dodecyl sulphate (3) were according to LIVINGSTON and KLEIN (8). The time for the precipitation was usually 1 hour, without any adverse effects. Plasmid DNA was precipitated from the supernatant by the addition of $1 / 4$ volume of $50 \%$ polyethylene glycol 6000 (Fluka) in water (4) and incubated for $1-2$ hours at $4^{\circ} \mathrm{C}$. It was collected in $12 \mathrm{ml}$ tubes at $15,000 \mathrm{rpm}$ in the Sorvall SS-34 rotor for 15 minutes, rinsed briefly in $70 \%$ ethanol and dissolved in electrophoresis buffer. Agarose gel electrophoresis was as described (5) but usually with a gel concentration of $1.5 \%$. At this concentration and a field intensity of $5 \mathrm{~V} \cdot \mathrm{cm}^{-1}$ both supercoiled and relaxed 2-micron DNA have lower mobilities than the chromosomal DNA present in excess. Maybe for that reason band positions are not detectably influenced by the amount of chromosomal DNA, an effect that was seen at lower gel concentration and field intensity, where the chromosomal DNA had the lowest mobility. In some cases we analysed samples that were further purified with conventional methods (RNase, pronase and/or phenol treatment, centrifugation with cesium chloride and ethidium bromide). Plasmid DNA preparations from the parents or the strains from which they were derived by mutagenesis were used as size markers.

\section{RESULTS}

\subsection{Nuclear genotypes of progeny}

Four crosses were carried out, all with one of the parents carrying karl. In two crosses a cir ${ }^{+}$ strain was mated to a cir ${ }^{\circ}$, whereas in the other two crosses both parents were $\mathrm{cir}^{+}$, but with different plasmid size. The small plasmid in strain $\mathrm{HQ} / 5 \mathrm{C}$ has been characterized by LIVINGSTON (6) to have one cleavage site for restriction endonuclease EcoRI. Strain K5-20B contains a slightly larger plasmid which we found to have two EcoRI sites.

In this paper the presence of the smaller and the larger plasmid are designated with $\mathrm{cir}^{+}-\mathrm{s}$ and $\mathrm{cir}^{+}-1$, respectively. The crossing technique was chosen such as to minimize multiple cycles of mating, i.e. mating of haploid progeny from the karl induced transient heterokaryons.

In all crosses one parent was erythromycin resistant and the other oligomycin resistant, so that some of the progeny from transient heterokaryons could be recovered by plating on YPG + ery + oli. In order to determine the approximate frequency of productive mating, the mating mixture was also plated on YPD and the colonies subsequently replicated onto media differentiating progeny and parents. Between 2 and $12 \%$ grew on YPG + ery + oli. From the direct YPG + ery + oli platings of each cross 100-240 colonies were picked, grown up and replicated to media chosen to differentiate between the two parental nuclear genotypes as 
M. C. Kielland-Brandt et al.: 2-micron DNA in yeast nuclei

Table II

Phenotypes of progeny and the occurrence and size of 2-micron DNA in cytoductants.

Cross A: C79-839 (MATa leul karl [ERY $\left.\left.\mathrm{cir}^{+}\right]\right) \times$C79-842 (MATa cyh [OLI cir'])

ERY OLI analysed for Leu

Haploid Leu+ analysed for cir

\begin{tabular}{|c|c|c|c|c|c|}
\hline Total & Leu- $^{-}$ & $\mathrm{Leu}^{+}$ & Total & $\operatorname{cir}^{+}$ & $\mathrm{cir}^{\circ}$ \\
\hline 240 & 0 & $240^{\mathrm{a}}$ & 8 & 2 & 6 \\
\hline
\end{tabular}

Cross B: C79-840 (MATa leul karl [OLI cir $\left.\left.{ }^{+}\right]\right) \times$C79-878 (MATa cyh[ERY cir $\left.{ }^{\circ}\right)$

ERY OLI analysed for Leu

Haploid Leu-analysed for cir

\begin{tabular}{lll} 
Total & Leu $^{-}$ & Leu $^{+}$ \\
\hline 100 & 25 & $75^{\mathrm{a}}$
\end{tabular}

\begin{tabular}{rrr} 
Total & cir $^{+}$ & cir $^{\circ}$ \\
\hline 8 & 8 & 0 \\
\hline
\end{tabular}

Haploid Leu ${ }^{+}$analysed for cir

\begin{tabular}{ccc} 
Total & $\mathrm{cir}^{+}$ & $\mathrm{cir}^{\circ}$ \\
\hline 6 & 3 & 3
\end{tabular}

Cross C: C79-839 (MATa leul karl [ERY cir $\left.\left.{ }^{+}-1\right]\right) \times$ C79-843 (MATa can [OLI $\mathrm{cir}^{+}-\mathrm{s}$ ])

ERY OLI analysed for Leu and Can

Haploid Leu ${ }^{+} \mathrm{Can}^{\mathrm{r}}$ analysed for cir

\begin{tabular}{cccc} 
Total & Leu $^{+}$Cans & Leu $^{+} \mathrm{Can}^{\mathrm{r}}$ & $\mathrm{Leu}^{-} \mathrm{Can}^{\mathrm{s}}$ \\
\hline 212 & $21^{\mathrm{b}}$ & 190 & 1
\end{tabular}

\begin{tabular}{ccc} 
Total & $\mathrm{cir}^{+}-\mathrm{l}$ & $\mathrm{cir}^{+}-\mathrm{s}$ \\
\hline 5 & 0 & 5 \\
\hline
\end{tabular}

Haploid Leu-Cans analysed for cir

\begin{tabular}{ccc} 
Total & $\operatorname{cir}^{+-1}$ & $\operatorname{cir}^{+}-\mathrm{s}$ \\
\hline 1 & 1 & 0 \\
\hline
\end{tabular}

Cross D: C79-840 (MATa leul karl [OLI cir $\left.\left.{ }^{+-1}\right]\right) \times$ C79-838 (MATa can [ERY $\left.\left.\mathrm{cir}^{+-}-\mathrm{s}\right]\right)$

ERY OLI analysed for Leu and Can

\begin{tabular}{|c|c|c|c|c|c|c|}
\hline Total & $\mathrm{Leu}^{+} \mathrm{Can}^{\mathrm{s}}$ & $\mathrm{Leu}^{+} \mathrm{Can}^{\mathrm{r}}$ & Leu-Cans & Total & $\operatorname{cir}^{+}-1$ & $\mathrm{cir}^{+}-\mathrm{s}$ \\
\hline 240 & $43^{b}$ & 197 & 0 & 7 & 0 & 7 \\
\hline
\end{tabular}

a includes diploids

b diploids

well as to reveal diploid progeny. The data are given in Table II.

In crosses $C$ and $D$ it should be noted that the gene for canavanine resistance, can, is recessive like the other markers, so that diploids will have the phenotype Leu ${ }^{+} \mathrm{Can}^{\mathrm{s}}$ (leucine prototrophic, canavanine sensitive). They occur at a frequency of $10-20 \%$, which is about the same as was found by CoNDE and FinK (2) in other karl $\times$ $K A R I$ crosses. In crosses $\mathrm{A}$ and $\mathrm{B}$ it was attempted to differentiate between diploids and the haploids of the $c y h$ genotype by replicating to YPD + cyh. The cyh gene turned out to be semidominant at the chosen drug concentration, since a few partly resistant progeny clones were found to be diploid when tested for their ability to sporulate. Not all progeny from crosses A and B were classified for cycloheximide resistance, but the frequency of diploids was in the same range as in crosses $\mathrm{C}$ and $\mathrm{D}$. Among the haploid 
progeny the karl nuclei are in the minority in all four crosses as seen by the low number of progeny of the Leu- phenotype. In fact, they appear only in two of the crosses and in one of these only as one out of 212 progeny clones. We have not investigated the reason for this differential recovery of parent nuclei.

\subsection{Analysis for 2-micron DNA and its size in cytoductants}

From each of the four crosses a number of presumed haploid progeny clones (ERY OLI) were taken at random, but including both parental nuclear genotypes when present. The clones were tested for sporulation and a few sporulators were discarded.

Each of the remaining clones was found to be homogeneous by plating approximately 200 cells on YPD and replicating the colonies to the appropriate media. Nucleic acid was extracted from each clone and analysed by agarose gel electrophoresis for the presence and size of 2micron DNA. Also these results are given in Table II and they may be summarized as follows: 1) In haploids from $\mathrm{a} \mathrm{cir}^{+} \times \mathrm{cir}^{\circ}$ cross the nuclei inherited from the $\mathrm{cir}^{+}$parent are always $(8$ out of 8 cases, cross B) accompanied by the plasmid, whereas the nuclei from the $\mathrm{cir}^{\circ}$ parent are accompanied by the plasmid in only $25-50 \%$ of the cases. 2) Haploids from a cir ${ }^{+}-1 \times \mathrm{cir}^{+}-\mathrm{s}$ cross have always ( 13 out of 13 cases) a plasmid size identical to the parent from which it had its nucleus. One of these 13 cytoductants had the nuclear genotype - and thus the plasmid size - of the $\mathrm{cir}^{+}-1$ parent. The sensitivity of the electrophoretic analysis does not exclude the possibility that in some of these cytoductants the other plasmid is present at a level of a few percent of the level of the detected plasmid.

\section{DISCUSSION}

The results of crosses $A$ and $B$ (Table II) closely follow Livingston (6) in that there are about equal numbers of $\mathrm{cir}^{+}$and $\mathrm{cir}^{\circ}$ progeny of the nuclear genotype of the $\mathrm{cir}^{\circ}$ parent. The analysis of the $\mathrm{Leu}^{-}$clones of cross $\mathrm{B}$, however, gives new information. The fact that they are all $\mathrm{Cir}^{+}$is hard to reconcile with the hypothesis that 2-micron DNA is clustered in a cytoplasmic organelle unless a close linkage of transmission between that organelle and the nucleus is postulated. We prefer the simpler interpretation that 2-micron DNA has a nuclear location and that one or a few copies of the plasmid may be transferred from one nucleus to another in karl mediated transient heterokaryons, resulting in a high frequency of $\mathrm{cir}^{+}$progeny of the genotype of the cir ${ }^{\circ}$ parent.

The results of crosses $\mathrm{C}$ and $\mathrm{D}$ are consistent with this interpretation. The size of 2-micron DNA is completely linked to the chromosomal markers. The possibility that the plasmid size might be determined by one or more Mendelian genes can be rejected with reference to LivingSTON (6). He found slow mitotic changes in either direction of the ratio of the amounts of a larger and a smaller species of 2-micron DNA and no segregation of the two types during meiosis.

It should be mentioned that CLARK-W ALKER and MikLos did not find 2-micron DNA in isolated nuclei (1). The plasmid DNA may have been lost during isolation of the nuclei.

Our proposal that the cir ${ }^{\circ}$ nuclei in crosses A and $\mathrm{B}$ are converted to $\mathrm{cir}^{+}$by the transfer of one or a few copies of the plasmid, seems to imply an amplification of the copy number, since the $\mathrm{cir}^{+}$ cytoductants did not appear to have less plasmid DNA than the $\mathrm{cir}^{+}$parent. The possibility that such amplification should occur by segregation and selection at the cellular level is not appealing, since the $\mathrm{cir}^{\circ}$ and the corresponding $\mathrm{cir}^{+}$progeny seem to grow equally well. We therefore propose that a low copy number of the plasmid relaxes the control which under normal conditions permits in one cell cycle only a single round of replication (16) of each 2-micron DNA molecule.

\section{ACKNOWLEDGEMENTS}

We wish to thank D. von WetTSTEIN for support and critical reading of the manuscript, J. CONDE for providing strain K5-20B, J. V. HANSEN for technical assistance and B. E. Christensen and $C$. Guermansen for interest and stimulating discussions. This work was supported by grant 511-15547, 512-15640 and 516-15099 from the Danish National Research Councils to D. vON WETTSTEIN. 


\section{REFERENCES}

1. Clark-Walker, G. D. \& G. L. G. Miklos: Localization and quantification of circular DNA in yeast. Eur. J. Biochem. 41, 359-365 (1974)

2. CONDE, J. \& G. R. Fink: A mutant of Saccharomyces cerevisiae defective for nuclear fusion. Proc. Nat. Acad. Sci. USA 73, 36513655 (1976)

3. HIRT, B.: Selective extraction of polyoma DNA from infected mouse cell cultures. J. Mol. Biol. $26,365-369(1967)$

4. Humphreys, G. O., G. A. Wlllshaw \& E. S. ANDERSON: A simple method for the preparation of large quantities of pure plasmid DNA. Biochim. Biophys. Acta 383, 457-463 (1975)

5. Kielland-Brandt, M. C., T. Nilsson-Tillgren, S. Holmberg, J. G. L Petersen \& B. A. SVENNINGSEN: Transformation of yeast without the use of foreign DNA. Carlsberg Res. Commun. 44, 77-87 (1979)

6. Livingston, D. M.: Inheritance of the $2 \mu \mathrm{m}$ DNA plasmid from Saccharomyces. Genetics 86, 7384 (1977)

7. Livingston, D. M. \& S. Hahne: Isolation of a condensed, intracellular form of the 2- $\mu \mathrm{m}$ DNA plasmid of Saccharomyces cerevisiae. Proc. Nat. Acad. Sci. USA 76, 3727-3731 (1979)

8. Livingston, D. M. \& H. L. Klein: Deoxyribonucleic acid sequence organization of a yeast plasmid. J. Bacteriol. 129, 472-481 (1977)

9. Livingston, D. M. \& D. M. Kupfer: Control of Saccharomyces cerevisiae $2 \mu \mathrm{m}$ DNA replication by cell division cycle genes that control nuclear
DNA replication. J. Mol. Biol. 116, 249-260 (1977)

10. Nelson, R. G. \& W. L. Fangman: Nucleosome organization of the yeast 2- $\mu \mathrm{m}$ DNA plasmid: A eukaryotic minichromosome. Proc. Nat. Acad. Sci., USA 76, 6515-6519 (1979)

11. Newlon, C. S. \& W. L. Fangman: Mitochondrial DNA synthesis in cell cycle mutants of Saccharomyces cerevisiae. Cell 5, 423-428 (1975)

12. Nilsson-Tillgren, T., J. G. L. Petersen, S. Holmberg \& M. C. Kielland-Brandt: Transfet of chromosome III during kar mediated cytoduction in yeast. Carlsberg Res. Commun. 45, 113-117 (1980)

13. Petersen, J. G. L., L. W. Olson \& D. Zickler: Synchronous sporulation of Saccharomyces cerevisiae at high cell concentrations. Carlsberg Res. Commun. 43, 241-253 (1978)

14. Putrament, A., H. Baranowska, A. Ejchart \& W. Prazmo: Manganese mutagenesis in yeast. A practical application of manganese for the induction of mitochondrial antibiotic-resistant mutations. J. Gen. Microbiol. 90, 265-270 (1975)

15. Schatffer, A. B. \& M. D. Fulton: A simplified method of staining endospores. Science 77, 194 (1933)

16. Zakian, V. A., B. J. Brewer \& W. L. FANGman: Replication of each copy of the yeast 2 micron DNA plasmid occurs during the $S$ phase. Cell $17,923-934$ (1979) 